\title{
ÓXIDO MISTO DE ÍTRIO-ALUMÍNIO DOPADO COM Eu(III)
}

Eduardo J. Nassar*, Lilian R. Avila, Paula F. S. Pereira, Omar J. de Lima, Lucas A. Rocha, Cesar Mello e Katia J. Ciuffi Universidade de Franca, Av. Dr. Armando Salles Oliveira, 201, 14404-600 Franca - SP

Luis D. Carlos

Departamento de Física, CICECO, Universidade de Aveiro, 3810-193 Aveiro - Portugal

Recebido em 12/3/04; aceito em 22/9/04; publicado na web em 28/1/05

\begin{abstract}
Eu(III)-DOPED ALUMINIUM YTTRIUM OXIDE. In this work, we report the synthesis and the photoluminescence features of $\mathrm{Eu}$ (III)-doped yttrium-aluminium oxide obtained by non-hydrolytic sol-gel routes. After heating the powders above $600{ }^{\circ} \mathrm{C}$ the XRD patterns show the presence of the $\mathrm{Y}_{4} \mathrm{Al}_{2} \mathrm{O}_{9}(\mathrm{YAM})$ and $\mathrm{Y}_{3} \mathrm{Al}_{5} \mathrm{O}_{12}$ (YAG) phases. At 800 and at $1500{ }^{\circ} \mathrm{C}$ the PL spectra display the $\mathrm{Eu}$ (III) lines characteristic of the YAM monoclinic phase. The ${ }^{5} \mathrm{D}_{0} \rightarrow{ }^{7} \mathrm{~F}_{2}$ transition is favored relatively to the ${ }^{5} \mathrm{D}_{0} \rightarrow{ }^{7} \mathrm{~F}_{1}$ lines. However, at $1100{ }^{\circ} \mathrm{C}$ the cubic YAG is the preferential phase and the ${ }^{5} \mathrm{D}_{0} \rightarrow{ }^{7} \mathrm{~F}_{1}$ transition dominates the spectrum. The Eu(III) ions lie in a centrosymmetrical site. The different solvents used in the sol-gel synthesis also change the relative proportion between these two phases. This is monitored analyzing the modifications in the relative intensity between the ${ }^{5} \mathrm{D}_{0} \rightarrow{ }^{7} \mathrm{~F}_{2}$ and the ${ }^{5} \mathrm{D}_{0} \rightarrow{ }^{7} \mathrm{~F}_{1}$ transitions.
\end{abstract}

Keywords: YAG; Eu III; sol-gel.

\section{INTRODUÇÃO}

Terras raras dopando vidro têm atraído a atenção da comunidade científica, devido às suas potenciais aplicações como dispositivos ópticos ${ }^{1}$. A química do sol-gel já é conhecida há bastante tempo, porém só nas últimas décadas tem sido explorada, principalmente pelo uso dos alcóxidos, os quais envolvem a produção de uma suspensão coloidal com subseqüente transformação em um gel viscoso e, posteriormente, um sólido ${ }^{2}$. Existe uma série de vantagens para o uso do processo sol-gel tradicional, tais como baixas temperaturas, incorporação de espécies orgânicas, entre outras, mas algumas limitações podem interferir no produto final, principalmente a sensibilidade dos precursores e a umidade.

O processo sol-gel não-hidrolítico recentemente desenvolvido tem sido empregado como metodologia alternativa, devido à sua versatilidade como método de preparação de óxidos inorgânicos ${ }^{3}$. A rota solgel não-hidrolítica envolve a reação de um haleto metálico com um doador de oxigênio, tal como álcool ou éter, para formar um alcóxido na ausência de umidade, com posterior formação do óxido inorgânico ${ }^{4}$. A literatura sobre essa metodologia tem aumentado nos últimos anos. O processo tem sido usado para a obtenção de óxido de alumínio e silício contendo diferentes tipos de compostos ${ }^{3,5-9}$.

Óxido misto de ítrio e alumínio possui particular interesse quando dopado com terras raras, principalmente devido a suas propriedades ópticas em lasers no estado sólido e luminóforos ${ }^{10-12}$. Esses materiais são normalmente sintetizados a altas temperaturas através de reações no estado sólido entre os óxidos de ítrio e alumínio. Tais condições induzem a vários problemas tais como tamanho de partículas e formação de diferentes fases ${ }^{9,10}$. A versatilidade do método sol-gel tem motivado a preparação de óxidos dopados com terras raras para aplicações fotônicas ${ }^{13-15}$.

A rota sol-gel não-hidrolítica pode ser utilizada para preparar óxido de ítrio-alumínio dopado com íons de terras raras. O controle da reação dos cloretos de ítrio, alumínio e európio realizado em tubo

*e-mail: ejnassar@unifran.br selado com temperatura e atmosfera controladas, utilizando álcoois e éteres como doadores de oxigênio para a formação in situ dos alcóxidos, e posterior tratamento térmico, conduz à formação dos óxidos mistos ${ }^{16}$, os quais tem despertado enorme interesse por apresentarem novas propriedades físico-químicas ${ }^{17}$.

Neste trabalho, reportamos a síntese e as propriedades luminescentes do íon Eu III dopando o óxido de ítrio e alumínio obtido pela rota sol-gel não-hidrolítica. A partir dos cloretos de ítrio e alumínio e éter diisopropílico ou etanol, como doadores de oxigênio, a mistura permaneceu em refluxo a uma temperatura constante em atmosfera de argônio. O cloreto de európio III foi utilizado como sonda estrutural. $\mathrm{O}$ gel formado foi tratado a 400, 800, 1100 e $1500{ }^{\circ} \mathrm{C}$. As amostras foram caracterizadas por difração de raios-X, microscopia eletrônica de varredura, análise termogravimétrica e fotoluminescência.

\section{PARTE EXPERIMENTAL}

\section{Preparação do óxido de ítrio-alumínio}

O material foi sintetizado via modificação do método descrito por $\mathrm{Acosta}^{6}$. 1,0 g de cloreto de alumínio $\left(\mathrm{AlCl}_{3}\right), 20 \mathrm{~mL}$ de cloreto de ítrio $0,10 \mathrm{~mol} / \mathrm{L}$ e $20 \mathrm{~mL}$ de etanol $(\mathrm{EtOH})$ ou éter diisopropílico $\left(i\right.$ - $\left.\mathrm{Pr}_{2} \mathrm{O}\right)$ foram usados como doadores de oxigênio. A essa mistura foi adicionado $1 \%$ de $\mathrm{EuCl}_{3}$ em relação ao alumínio. A mistura permaneceu em refluxo por $3 \mathrm{~h}$ a $110{ }^{\circ} \mathrm{C}$, em $50 \mathrm{~mL}$ de diclorometano (previamente destilado) sob atmosfera de argônio. $\mathrm{O}$ condensador foi acoplado a um banho termostático, e a temperatura foi mantida em $-5{ }^{\circ} \mathrm{C}$. Depois de $90 \mathrm{~min}$ formou-se o gel; o sólido foi obtido após a remoção do solvente sob vácuo. $\mathrm{O}$ sólido sofreu tratamento térmico em temperaturas de 400, 800, 1100 e $1500{ }^{\circ} \mathrm{C}$ durante $3 \mathrm{~h}$.

\section{Análise termogravimétrica (TGA/DTA)}

A análise termogravimétricafoi realizada em um Thermal Analyst 5000 - TA Instruments SDT Q 600 TGA-DTA, em atmosfera de nitrogênio, com vazão de $100 \mathrm{~mL} / \mathrm{min}$ e razão de aquecimento de $10{ }^{\circ} \mathrm{C} \mathrm{min}^{-1}$, no intervalo de temperatura de 25 a $1500{ }^{\circ} \mathrm{C}$. 


\section{Difração de raios-X (DRX)}

As medidas de difração de raios- $\mathrm{X}$ foram realizadas à temperatura ambiente em um Rigaku Geigerflex D/max-c "diffractometer system" usando radiação $\mathrm{CuK} \alpha(\lambda=1,54 \AA), 2 \theta$ entre 4 e $80^{\circ}$, com resolução de $0,05^{\circ}$. Utilizou-se como base de dados dos raios-X o ICDD-PDF-4.

\section{Fotoluminescência (FL)}

Os espectros de emissão e excitação foram obtidos à temperatura ambiente em um espectrofluorimetro Jobin Yvon-Spex (HR 460), utilizando uma fotomultiplicadora Hamamatsu R928. Utilizou-se como fonte de excitação uma lâmpada de Xe (150 mW) acoplada a um monocromador (TRIAX 180). Todos os espectros de excitação foram corrigidos, subtraindo-se o espectro da lâmpada.

\section{Microscopia eletrônica de varredura (MEV)}

As imagens de microscopia eletrônica de varredura foram registradas em um microscópio Hitachi S-4100, com potência de $25 \mathrm{kV}$. As amostras foram previamente cobertas com um filme de carbono.

\section{RESULTADOS E DISCUSSÃO}

\section{Difração de raios-X (DRX)}

As Figuras 1 e 2 apresentam o DRX do óxido misto preparado com éter e álcool, como doadores de oxigênio, respectivamente. Podese observar a presença de diferentes fases do óxido misto de ítrio e alumínio, independente do doador de oxigênio utilizado na preparação da amostra. Após a secagem a $100{ }^{\circ} \mathrm{C}$, o difratograma apresentou uma mistura de cloreto de ítrio e alumínio. O tratamento a $400{ }^{\circ} \mathrm{C}$ apresentou estrutura amorfa; a $700{ }^{\circ} \mathrm{C}$ o óxido começou a apresentar estrutura organizada e várias fases apareceram, tais como $\mathrm{AlCl}_{3} \cdot 6 \mathrm{H}_{2} \mathrm{O}$, $\mathrm{YCl}_{3} .6 \mathrm{H}_{2} \mathrm{O}, \mathrm{AlEuO}_{3}, \mathrm{EuOCl}, \mathrm{YOCl}, \mathrm{Y}_{2} \mathrm{O}_{3}, \mathrm{Al}_{2} \mathrm{O}_{3},\left(\mathrm{Y}_{.95} \mathrm{Eu}_{.05}\right) \mathrm{O}_{3}$, $\mathrm{Al}_{2} \mathrm{Y}_{4} \mathrm{O}_{9}$ e $\mathrm{Al}_{5} \mathrm{Y}_{3} \mathrm{O}_{12}$.

Em todos os DRX não foram observados picos referentes ao óxido de európio, indicando que o íon Eu III está fazendo parte da estrutura, provavelmente ocupando a posição do ítrio no material.

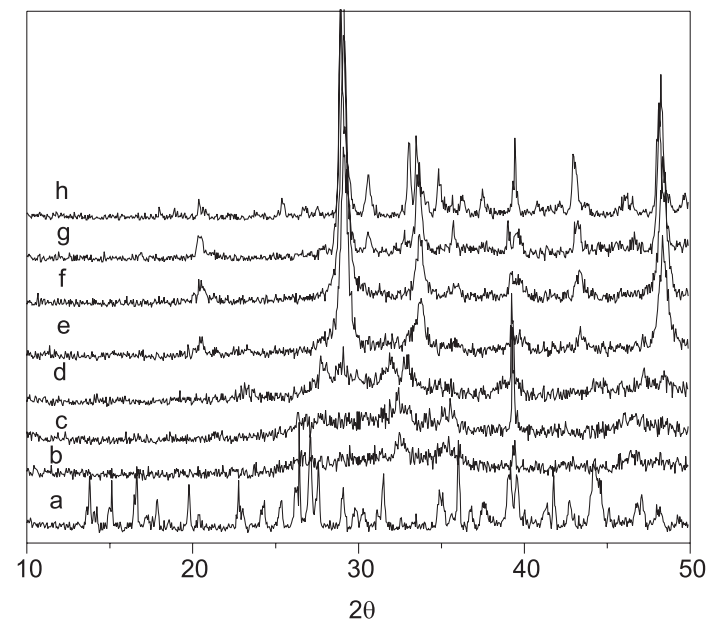

Figura 1. DRX para a amostra preparada com éter como doador de oxigênio em função da temperatura: a) 100 , b) 400, c) 500, d) 600, e) 700, f) 800, g) $1100 \mathrm{e} \mathrm{h)} 1500^{\circ} \mathrm{C}$

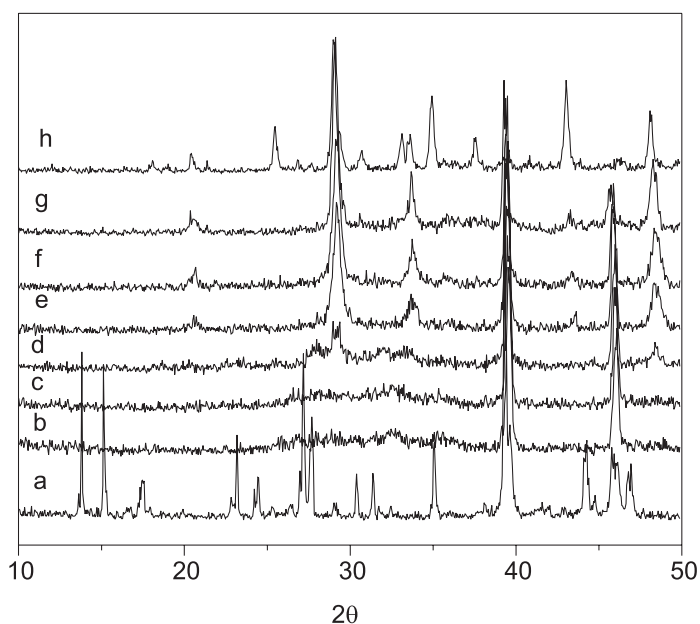

Figura 2. DRX para a amostra preparada com álcool como doador de oxigênio em função da temperatura: a) 100 , b) 400, c) 500, d) 600, e) 700, f) $800, \mathrm{~g}) 1100 \mathrm{e} \mathrm{h)} 1500^{\circ} \mathrm{C}$

Na temperatura de $100{ }^{\circ} \mathrm{C}$ observou-se $2 \theta$ característicos dos cloretos de ítrio e alumínio; a partir de $700{ }^{\circ} \mathrm{C}$ os picos aparecem em $2 \theta$ em torno de $31^{\circ}$, característico da fase $\mathrm{Al}_{2} \mathrm{Y}_{4} \mathrm{O}_{9}(\mathrm{YAM})$ e $33^{\circ}$, característico do $\mathrm{Al}_{5} \mathrm{Y}_{3} \mathrm{O}_{12}$ (YAG).

\section{TGA-DTA}

As análises termogravimétricas das amostras apresentaram três transformações endotérmicas distintas a 100,200 e $400{ }^{\circ} \mathrm{C}$, as quais podem ser atribuídas à perda de moléculas de água e do solvente, como se pode ver nas Figuras 3a, 3b, 4a e 4b. A amostra obtida utilizando EtOH como doador de oxigênio apresentou uma perda de massa de $58 \%$, já para o $i-\operatorname{Pr}_{2} \mathrm{O}$ a perda de massa é de $63 \%$. A perda de massa ocorre principalmente entre 120 e $300^{\circ} \mathrm{C}$. A análise térmica diferencial indica uma transformação exotérmica a $870{ }^{\circ} \mathrm{C}$, a qual foi atribuída a uma transição de fase, provavelmente dos óxidos de ítrio e alumínio em óxidos mistos, pois a partir de $800{ }^{\circ} \mathrm{C}$ os picos em $31^{\circ}$ e $33^{\circ}$ são observados no DRX .

\section{Microscopia eletrônica de varredura (MEV)}

As Figuras 5 e 6 apresentam as imagens das amostras preparadas com os diferentes doadores de oxigênio, tratadas a 1100 e $1500{ }^{\circ} \mathrm{C}$. A Figura 5 apresenta o MEV da amostra preparada com etanol e a Figura 6, com éter.

As imagens da microscopia mostraram que as amostras preparadas com éter como doador estão mais densas que as preparadas com etanol como doador. A evaporação rápida do solvente conduz à densificação do material, levando à formação de uma estrutura irreversível, isto é observado na amostra preparada com éter como doador de oxigênio, tendo a estrutura do YAG como fase preferencial. A lenta evaporação do etanol conduziu à formação do YAG a $1100{ }^{\circ} \mathrm{C}$ porém, quando tratada a $1500{ }^{\circ} \mathrm{C}$, a fase preferencial é a estrutura do YAM.

\section{Propriedades luminescentes}

As Figuras 7 e 8 mostram os espectros do íon Eu III dopando o óxido de ítrio-alumínio, para as amostras preparadas a partir do EtOH e $i-\operatorname{Pr}_{2} \mathrm{O}$ como doadores de oxigênio, respectivamente. $\mathrm{O}$ máximo de emissão foi fixado em $611 \mathrm{~nm}\left({ }^{5} \mathrm{D}_{0} \rightarrow{ }^{7} \mathrm{~F}_{2}\right)$. As linhas finas foram atribuídas às transições entre os níveis ${ }^{7} \mathrm{~F}_{0} \mathrm{e}^{5} \mathrm{~L}_{6},{ }^{5} \mathrm{D}_{1-3}$. 

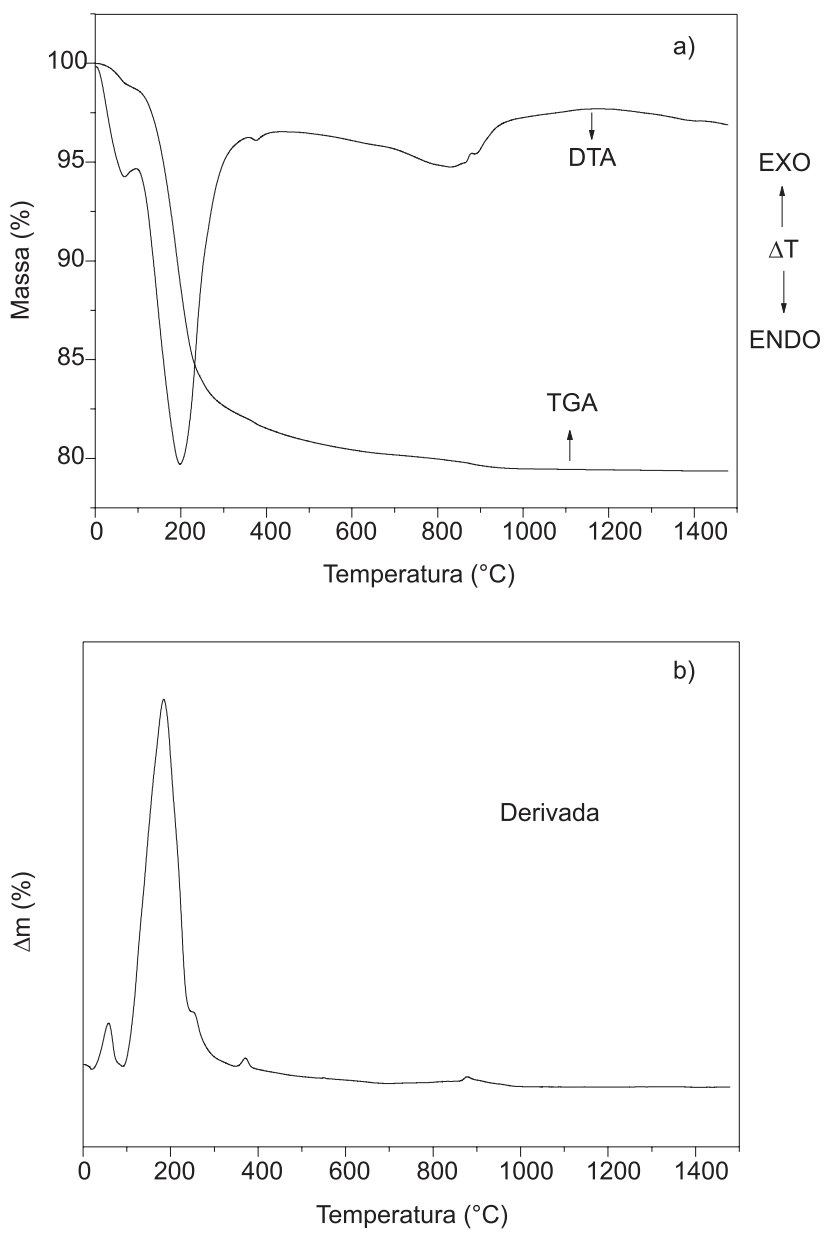

Figura 3. Curvas termogravimétricas da amostra preparada com éter como doador de oxigênio: a) TGA e DTA e b) Derivada

a)

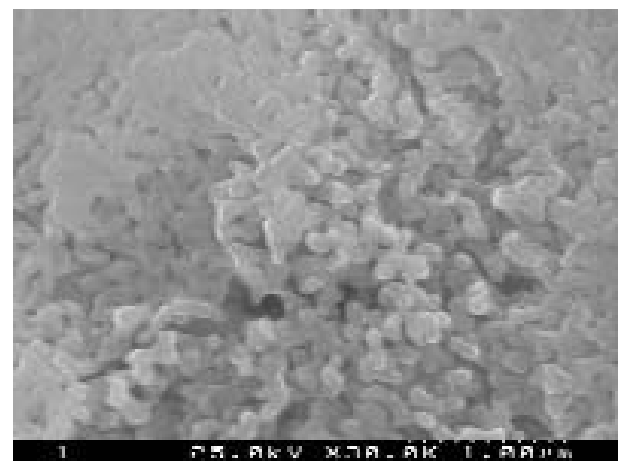

b)

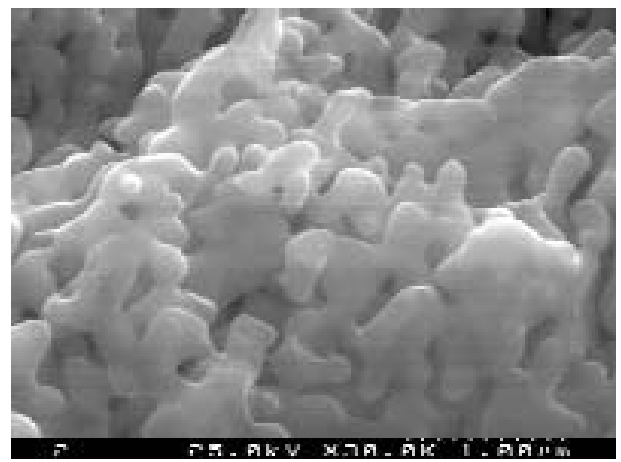

Figura 5. MEV da amostra preparada com álcool como doador de oxigênio tratada a: a) 1100 e b) $1500{ }^{\circ} \mathrm{C}$
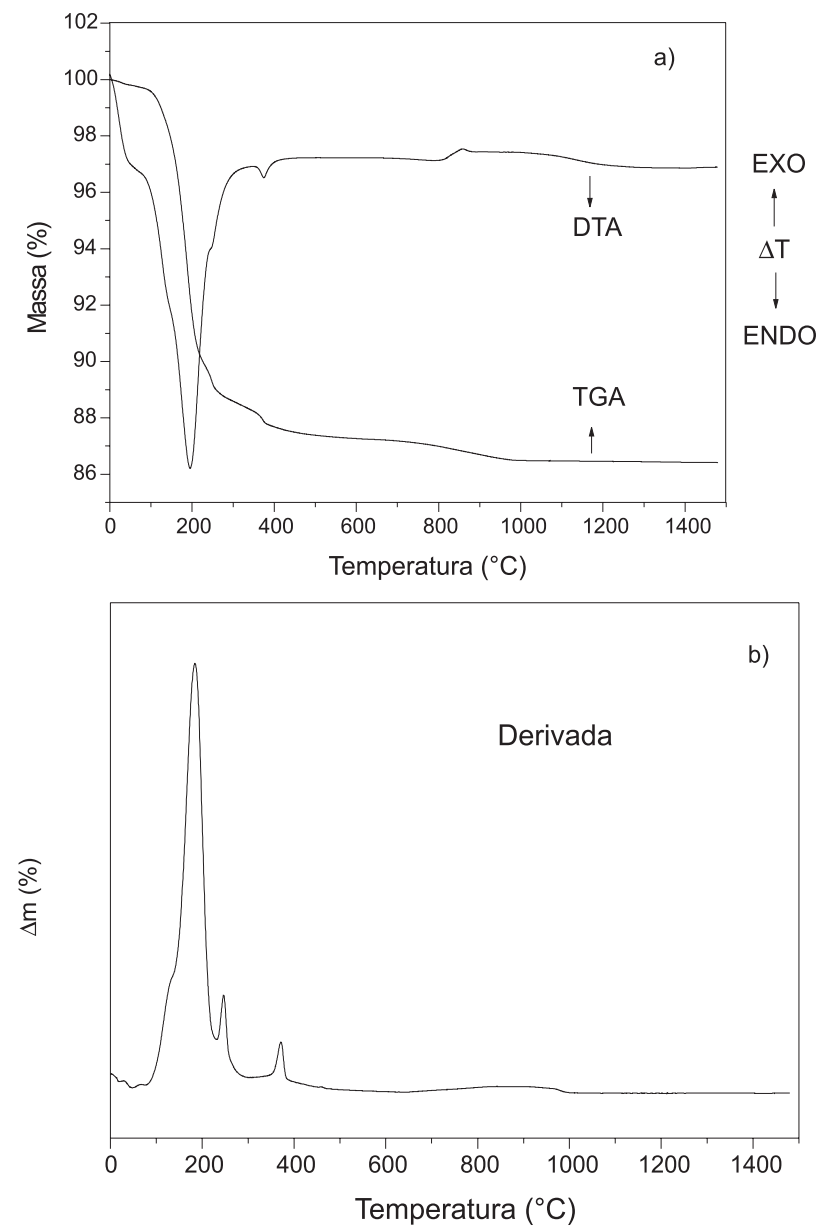

Figura 4. Curvas termogravimétricas da amostra preparada com álcool como doador de oxigênio: a) TGA e DTA e b) Derivada

a)

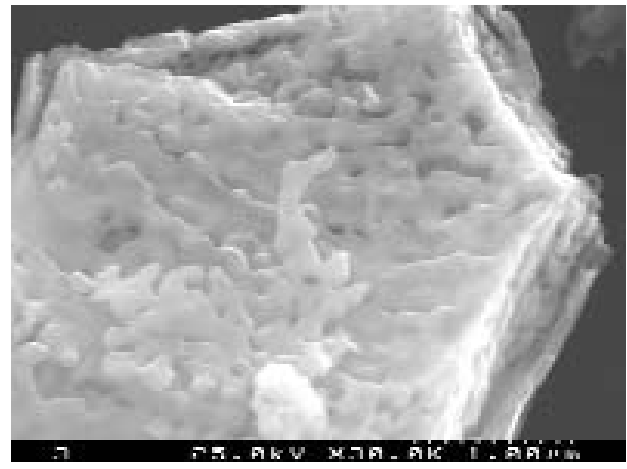

b)

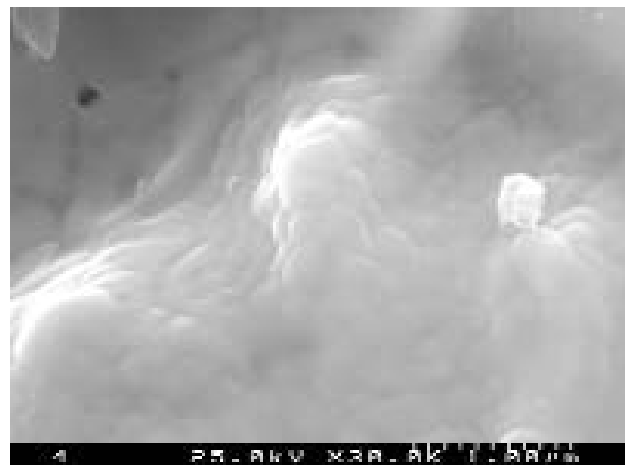

Figura 6. MEV da amostra preparada com éter como doador de oxigênio tratada a: a) 1100 e b) $1500{ }^{\circ} \mathrm{C}$ 


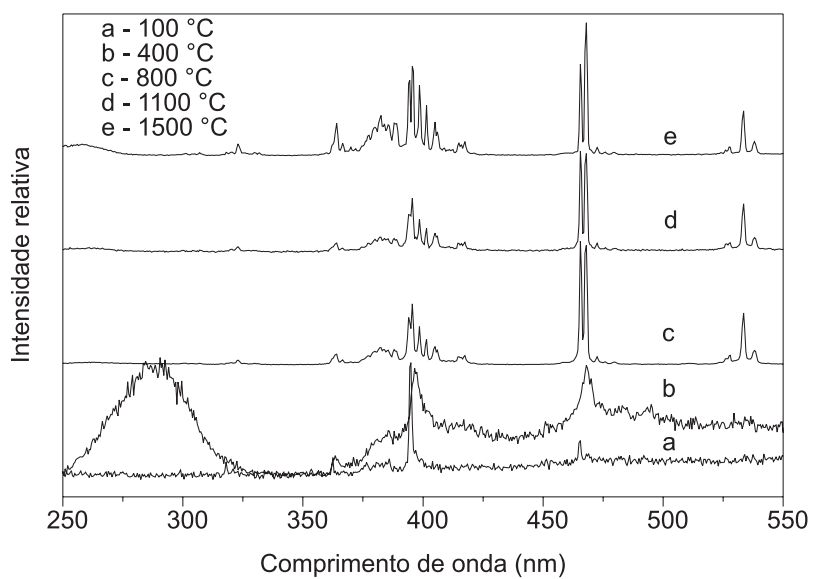

Figura 7. Espectros de excitação das amostras preparadas com álcool como doador de oxigênio em diferentes temperaturas, $\lambda_{e m}=611 \mathrm{~nm}\left({ }^{5} D_{0} \rightarrow{ }^{7} F_{2}\right)$

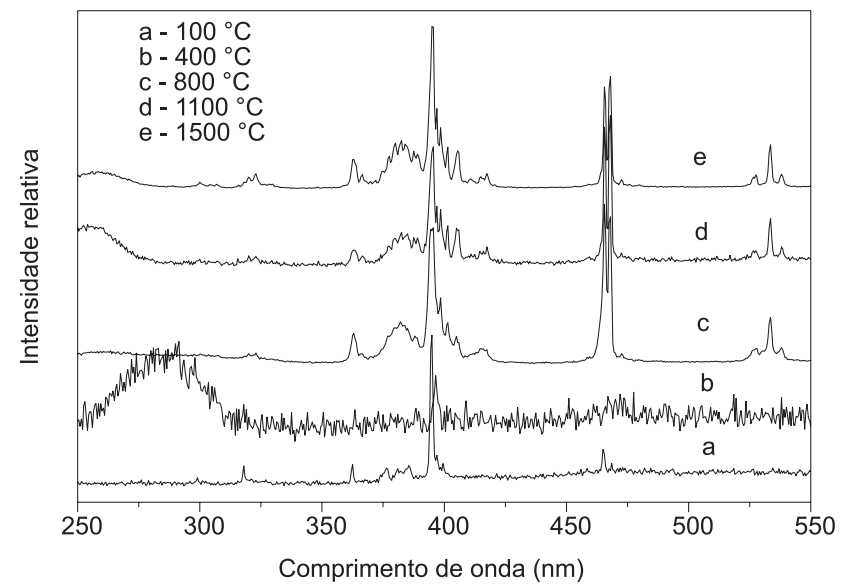

Figura 8. Espectros de excitação das amostras preparadas com éter como doador de oxigênio em diferentes temperaturas, $\lambda_{e m}=611 \mathrm{~nm}\left({ }^{5} D_{0} \rightarrow{ }^{7} F_{2}\right)$

Os espectros de excitação para as amostras tratadas a $400{ }^{\circ} \mathrm{C}$ apresentam banda de transferência de carga (BTC) em $288 \mathrm{~nm}$ para o doador EtOH e $290 \mathrm{~nm}$ para o $i-\mathrm{Pr}_{2} \mathrm{O}$. As amostras tratadas a $800{ }^{\circ} \mathrm{C}$ não apresentam a BTC. Para as amostras tratadas a 1100 e $1500{ }^{\circ} \mathrm{C}$ observa-se pequena banda na região de maior energia, ao redor de $260 \mathrm{~nm}$, correspondente à matrix $\mathrm{Y}_{2} \mathrm{O}_{3}{ }^{18}$.

A amostra preparada com o álcool apresenta espectro favorecendo a transição ${ }^{5} \mathrm{D}_{2}(466 \mathrm{~nm})$, ao passo que o éter favorece a transição ${ }^{5} \mathrm{~L}_{6}(394 \mathrm{~nm})$, como pode ser observado nas Figuras 7 e 8 . Os espectros de emissão do íon Eu III na matriz ítrio-alumínio excitado em $395 \mathrm{~nm}$, nível ${ }^{5} \mathrm{~L}_{6}$, são mostrados nas Figuras 9 e 10, tendo como doadores de oxigênio álcool e éter, respectivamente.

Na Figura 9, onde se utilizou álcool como doador de oxigênio, observaram-se semelhanças espectrais nas amostras tratadas a $800 \mathrm{e}$ $1500{ }^{\circ} \mathrm{C}$; já a tratada a $1100{ }^{\circ} \mathrm{C}$ apresenta uma nova fase. Na Figura 10 a fase favorecida é a mesma para as três temperaturas.

A Tabela 1 apresenta os comprimentos de onda de emissão para as amostras preparadas com etanol e éter.

As amostras obtidas utilizando álcool como doador de oxigênio apresentam três bandas na região da transição ${ }^{5} \mathrm{D}_{0} \rightarrow{ }^{7} \mathrm{~F}_{0}$, uma fraca banda em 578,5 $\mathrm{nm}$ aparece na amostra tratada a 800 e $1100{ }^{\circ} \mathrm{C}$ e desaparecendo em $1500{ }^{\circ} \mathrm{C}$. Um comportamento similar é observado para as bandas em 590,4, 591,1 e 596,4 nm, correspondente à transição ${ }^{5} \mathrm{D}_{0} \rightarrow{ }^{7} \mathrm{~F}_{1}$. A transição ${ }^{5} \mathrm{D}_{0} \rightarrow{ }^{7} \mathrm{~F}_{1}$ é a mais importante no espectro da amostra tratada a $1100{ }^{\circ} \mathrm{C}$, indicando a fase cúbica como a prefe-

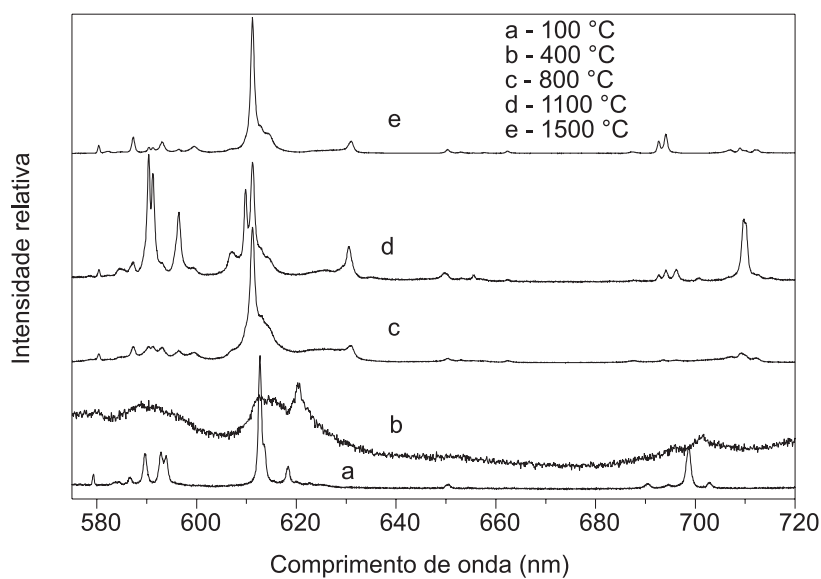

Figura 9. Espectros de emissão para as amostras preparadas com álcool como doador de oxigênio em diferentes temperaturas, $\lambda_{\text {exc }}=395 \mathrm{~nm}$

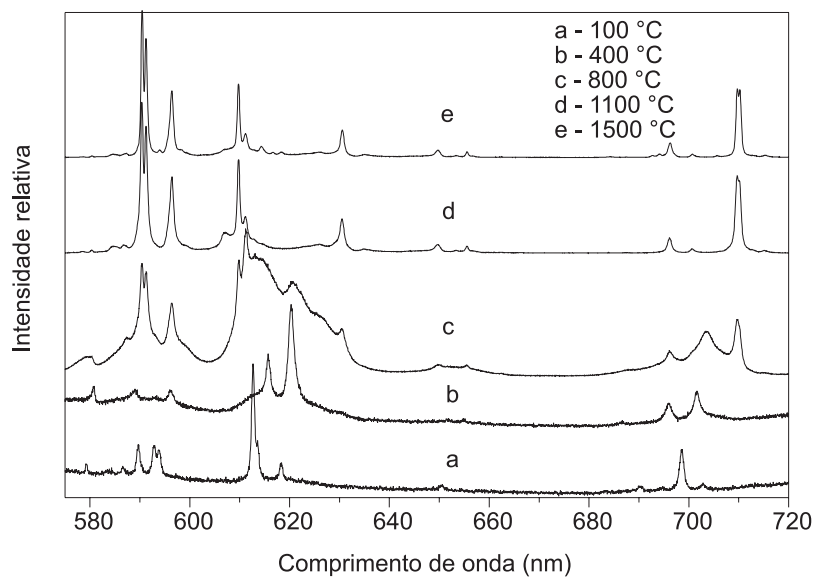

Figura 10. Espectros de emissão para as amostras preparadas com éter como doador de oxigênio em diferentes temperaturas, $\lambda_{\text {exc }}=395 \mathrm{~nm}$

rencial do YAG. A $1500^{\circ} \mathrm{C}$ a fase preferencial é a monoclínica relativa ao YAM.

Para as amostras preparadas com éter como doador de oxigênio, a fase YAG é formada a $800{ }^{\circ} \mathrm{C}$ e permanece até $1500{ }^{\circ} \mathrm{C}$.

A transição ${ }^{5} \mathrm{D}_{0} \rightarrow{ }^{7} \mathrm{~F}_{2}$ ocorre através de um mecanismo de dipolo elétrico; ela é chamada de transição hipersensitiva, visto que a intensidade relativa é facilmente alterada quando ocorrem alterações estruturais no ambiente do íon. A transição ${ }^{5} \mathrm{D}_{0} \rightarrow{ }^{7} \mathrm{~F}_{1}$ é de natureza dipolo magnético e é muito pouco afetada pelas mudanças estruturais. A razão das áreas das bandas relativas às transições ${ }^{5} \mathrm{D}_{0} \rightarrow{ }^{7} \mathrm{~F}_{2} /$ ${ }^{5} \mathrm{D}_{0} \rightarrow{ }^{7} \mathrm{~F}_{1}$ no espetro de emissão indica um sítio de simetria relativa, visto que a intensidade será zero quando o íon está em um centro de simetria, e pode ser largo em sítios distorcidos ${ }^{19}$. Isto é observado em nossos espectros de emissão na transição de fases entre YAG e YAM.

A fase cristalina $\mathrm{Al}_{2} \mathrm{Y}_{4} \mathrm{O}_{9}$ monoclínica tem três sítios cristalográficos distintos, dois de baixa simetria, cada com o grupo pontual $\mathrm{C}_{\mathrm{s}}{ }^{20}$. $\mathrm{O}$ terceiro sítio pode ser descrito com um octaedro distorcido, com sete oxigênios a uma distância maior ${ }^{21}$. Este fato explica a maior intensidade da transição ${ }^{5} \mathrm{D}_{0} \rightarrow{ }^{7} \mathrm{~F}_{2}$ em relação a ${ }^{5} \mathrm{D}_{0} \rightarrow{ }^{7} \mathrm{~F}_{1}$.

A fase cúbica $\mathrm{Al}_{5} \mathrm{Y}_{3} \mathrm{O}_{12}$ dopada com íons Eu III ocupa as posições do Y III. Nesta fase o Eu III ocupa dois diferentes sítios cristalográficos ${ }^{22}$, que são os sítios $\mathrm{S}_{6}$ e $\mathrm{C}_{2}$. O sítio $\mathrm{S}_{6}$ tem o nível ${ }^{5} \mathrm{D}_{0}$ $87 \mathrm{~cm}^{-1}$ mais alto que o ${ }^{5} \mathrm{D}_{0}$ do $\mathrm{C}_{2}{ }^{23}$.

As Figuras 11 e 12 mostram os espectros de emissão do íon Eu 
III na matriz de alumínio/ítrio quando excitado em $464 \mathrm{~nm}$, preparadas em álcool e éter como doadores de oxigênio, respectivamente.

Observa-se a emissão preferencial do YAM quando excitado no

Tabela 1. Comprimento de onda das transições ${ }^{5} \mathrm{D}_{0} \rightarrow{ }^{7} \mathrm{~F}_{\mathrm{J}}(\mathrm{J}=0,1$, 2 ,4) para as amostras tratadas a 800,1100 e $1500{ }^{\circ} \mathrm{C}$, monitorado a $395 \mathrm{~nm}$, para a matriz de ítrio-alumínio preparadas com etano (EtOH) e éter diisopropílico $\left(i-\mathrm{Pr}_{2} \mathrm{O}\right)$ como doadores de oxigênio

\begin{tabular}{|c|c|c|c|c|}
\hline amostras & ${ }^{5} \mathrm{D}_{0} \rightarrow{ }^{7} \mathrm{~F}_{0}$ & ${ }^{5} \mathrm{D}_{0} \rightarrow{ }^{7} \mathrm{~F}_{1}$ & ${ }^{5} \mathrm{D}_{0} \rightarrow{ }^{7} \mathrm{~F}_{2}$ & ${ }^{5} \mathrm{D}_{0} \rightarrow{ }^{7} \mathrm{~F}_{4}$ \\
\hline $\begin{array}{l}800^{\circ} \mathrm{C} \\
(\mathrm{EtOH})\end{array}$ & $\begin{array}{l}578,5 \\
580,5 \\
584,4\end{array}$ & $\begin{array}{l}587,4 \\
590,2 \\
591,1 \\
593,1 \\
596,4 \\
599,4\end{array}$ & $\begin{array}{l}606,0 \\
611,2 \\
614,7 \\
625,2 \\
630,9\end{array}$ & $\begin{array}{l}687,5 \\
693,3 \\
696,3 \\
707,2 \\
709,3 \\
712,2\end{array}$ \\
\hline $\begin{array}{l}1100{ }^{\circ} \mathrm{C} \\
(\mathrm{EtOH})\end{array}$ & $\begin{array}{l}578,6 \\
580,4 \\
584,5\end{array}$ & $\begin{array}{l}587,2 \\
590,4 \\
591,2 \\
593,1 \\
596,4 \\
599,3\end{array}$ & $\begin{array}{l}607,1 \\
609,8 \\
611,3 \\
612,8 \\
614,5 \\
625,7 \\
630,5\end{array}$ & $\begin{array}{l}692,7 \\
694,1 \\
696,1 \\
700,7 \\
709,7 \\
710,1 \\
712,7 \\
715,2\end{array}$ \\
\hline $\begin{array}{l}1500{ }^{\circ} \mathrm{C} \\
(\mathrm{EtOH})\end{array}$ & $\begin{array}{l}580,4 \\
582,2 \\
584,8\end{array}$ & $\begin{array}{l}587,4 \\
590,5 \\
591,2 \\
593,2 \\
596,5 \\
599,6\end{array}$ & $\begin{array}{l}611,3 \\
612,8 \\
614,4 \\
631,0\end{array}$ & $\begin{array}{l}692,7 \\
694,1 \\
706,9 \\
709,0 \\
709,9 \\
712,3\end{array}$ \\
\hline $\begin{array}{l}800{ }^{\circ} \mathrm{C} \\
\left(i-\operatorname{Pr}_{2} \mathrm{O}\right)\end{array}$ & 579,9 (larga) & $\begin{array}{l}587,4 \\
590,4 \\
591,3 \\
593,0 \\
596,4 \\
598,9\end{array}$ & $\begin{array}{l}609,9 \\
611,2 \\
614,4 \\
620,7 \\
626,2 \\
630,4\end{array}$ & $\begin{array}{l}696,1 \\
703,6 \\
709,8\end{array}$ \\
\hline $\begin{array}{l}1100{ }^{\circ} \mathrm{C} \\
\left(i-\operatorname{Pr}_{2} \mathrm{O}\right)\end{array}$ & $\begin{array}{l}578,5 \\
580,4 \\
584,6\end{array}$ & $\begin{array}{l}586,8 \\
590,4 \\
591,2 \\
596,4 \\
599,3\end{array}$ & $\begin{array}{l}606,9 \\
609,8 \\
611,2 \\
612,8 \\
626,0 \\
630,5\end{array}$ & $\begin{array}{l}696,2 \\
700,7 \\
709,8 \\
715,2\end{array}$ \\
\hline $\begin{array}{l}1500{ }^{\circ} \mathrm{C} \\
\left(i-\operatorname{Pr}_{2} \mathrm{O}\right)\end{array}$ & $\begin{array}{l}578,6 \\
580,4 \\
584,7\end{array}$ & $\begin{array}{l}587,2 \\
290,4 \\
291,3 \\
293,9 \\
596,4 \\
598,5\end{array}$ & $\begin{array}{l}606,8 \\
609,7 \\
611,2 \\
614,3 \\
616,7 \\
618,3 \\
625,9 \\
630,5\end{array}$ & $\begin{array}{l}692,7 \\
694,1 \\
696,3 \\
700,8 \\
705,7 \\
709,7 \\
710,2 \\
715,3\end{array}$ \\
\hline
\end{tabular}

nível ${ }^{5} \mathrm{D}_{2}$ para as amostras preparadas com álcool. Para as amostras preparadas com éter observou-se fraca emissão da fase YAG quando excitado em $464 \mathrm{~nm}$.

Na Tabela 2 são apresentados os tempos de vida para as transições ${ }^{5} \mathrm{D}_{0} \rightarrow{ }^{7} \mathrm{~F}_{2} \mathrm{e}^{5} \mathrm{D}_{0} \rightarrow{ }^{7} \mathrm{~F}_{1}$ do íon Eu III na matriz de alumínio/ítrio preparadas com diferentes doadores de oxigênio a diferentes temperaturas.

O tempo de vida acima de 1,00 ms sugere ambiente sem moléculas de água. O tempo de vida da transição em $611 \mathrm{~nm}$, excitado em diferentes comprimentos de onda (395 e $464 \mathrm{~nm}$ ) apresenta valores similares; isto se deve à contribuição apenas da fase YAM. O elevado

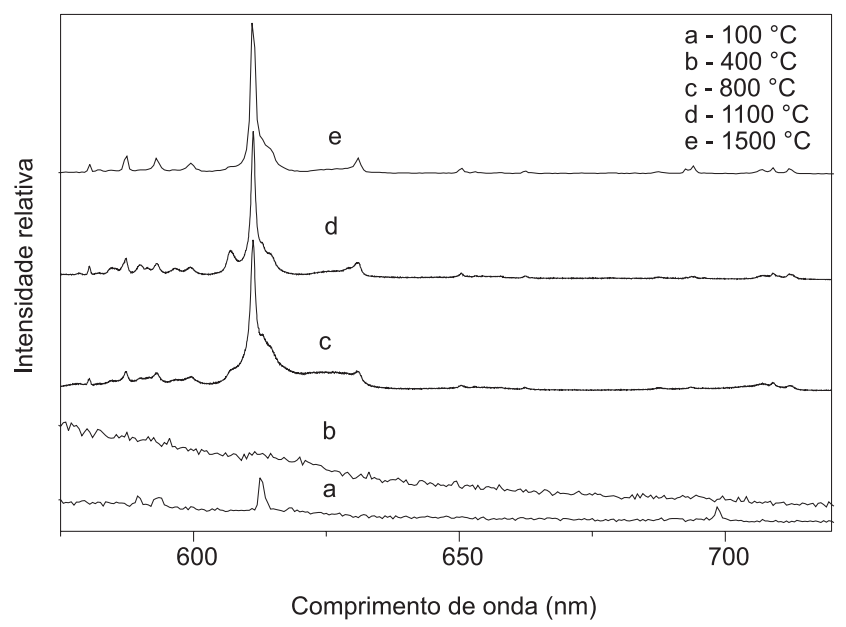

Figura 11. Espectros de emissão das amostras preparadas com álcool como doador de oxigênio em diferentes temperaturas de tratamento, excitado em $464 \mathrm{~nm}$ (nivel ${ }^{5} \mathrm{D}_{2}$ )

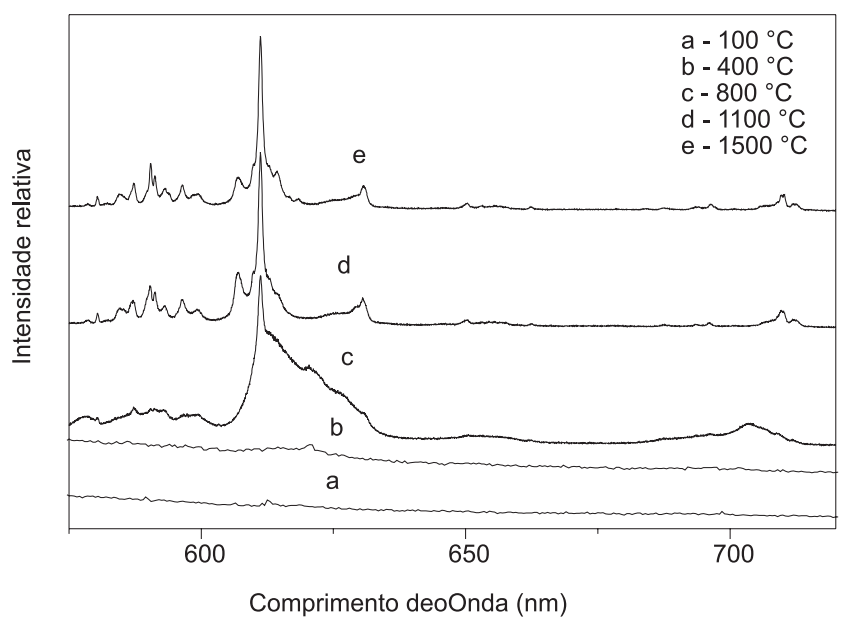

Figura 12. Espectros de emissão das amostras preparadas com éter como doador de oxigênio em diferentes temperaturas de tratamento, excitado em $464 \mathrm{~nm}$ (nivel ${ }^{5} \mathrm{D}_{2}$ )

Tabela 2. Tempo de vida (ms) para as transições ${ }^{5} \mathrm{D}_{0} \rightarrow{ }^{7} \mathrm{~F}_{2}$ e ${ }^{5} \mathrm{D}_{0} \rightarrow{ }^{7} \mathrm{~F}_{1}$ do íon Eu III na matriz de alumínio/ítrio preparadas com diferentes doadores de oxigênio a diferentes temperaturas. Monitorado a 395 e $611 \mathrm{~nm}$

\begin{tabular}{|c|c|c|c|c|c|c|}
\hline \multirow[t]{2}{*}{ Amostra/transição } & \multicolumn{3}{|c|}{$\mathrm{EtOH}$} & \multicolumn{3}{|c|}{$i-\mathrm{Pr}_{2} \mathrm{O}$} \\
\hline & $800^{\circ} \mathrm{C}$ & $1100{ }^{\circ} \mathrm{C}$ & $1500^{\circ} \mathrm{C}$ & $800^{\circ} \mathrm{C}$ & $1100^{\circ} \mathrm{C}$ & $1500{ }^{\circ} \mathrm{C}$ \\
\hline $464 \mathrm{~nm}-611 \mathrm{~nm}$ & 1,81 & 1,67 & 0,98 & 1,48 & 1,65 & 1,12 \\
\hline $395 \mathrm{~nm}-611 \mathrm{~nm}$ & 1,81 & - & 1,03 & 1,44 & - & - \\
\hline $395 \mathrm{~nm}-590 \mathrm{~nm}$ & - & 4,92 & - & - & 4,55 & 3,53 \\
\hline
\end{tabular}


tempo de vida da transição ${ }^{5} \mathrm{D}_{0} \rightarrow{ }^{7} \mathrm{~F}_{1}$ em $590 \mathrm{~nm}$ está relacionado somente com a fase YAG.

\section{CONCLUSÃO}

A presente investigação demonstra a preparação de óxidos de alumínio/ítrio pela rota sol-gel não-hidrolítica. A fase formada depende do tipo de doador de oxigênio utilizado na preparação in situ do alcóxido de alumínio e ítrio.

A fase YAG pode ser obtida a baixas temperaturas, a $800{ }^{\circ} \mathrm{C}$ foi observada a formação da estrutura do YAG quando se utilizou éter diisopropílico como doador de oxigênio.

Os tempos de vida confirmaram a presença de diferentes fases estruturais.

A metodologia sol-gel não-hidrolítica é um processo eficiente na preparação de matrizes mistas contendo alumínio/ítrio bem como apresenta boas condições para obtenção do YAG a baixas temperaturas.

\section{AGRADECIMENTOS}

Os autores agradecem à FAPESP pelas bolsas e auxílios concedidos. A Dra. R. A. Sá Ferreira, da Universidade de Aveiro pela ajuda nas medidas de fotoluminescência.

\section{REFERENNCIAS}

1. Nogami, M.; Nagakura, T.; Hayakawa, T.; J. Lumin. 2000, 86, 117.

2. Weight, J. D.; Sommerdijk, N. A. J. M. Em Sol-Gel Materials Chemistry and Applications; Eds. Taylor \& Francis Books, 2003.
3. Apperley, D.; Hay, J. N.; Raval, H. M.; Chem. Mater. 2002, 14, 983.

4. Hay, J. N.; Raval, H. M.; Chem. Mater. 2001, 13, 3396.

5. Calléja, G.; Cerveau, G.; Corriu, R. J. P.; J. Organomet. Chem. 2001, 621, 46.

6. Acosta, S.; Corriu, R. J. P.; Leclercq, D.; Lefèvre, P.; Mutin, P. H.; Vioux, A.; J. Non-Cryst. Solids 1994, 170, 234.

7. Janackovic, D.; Orlovic, A.; Skala, D.; Drmanic, S.; Kostic-Gvozdenovic, L.; Jokanovic, V.; Uskokovic, D.; Nonostructured Materials 1999, 12, 147.

8. Ciuffi, K. J.; de Lima, O. J.; Sacco, H. C.; Nassar, E. J.; J. Non-Cryst Solids 2002, 304, 126.

9. de Lima, O. J.; de Aguirre, D. P.; de Oliveira, D. C.; da Silva, M. A.; Mello, C.; Leite, C. A. P.; Sacco, H. C.; Ciuffi, K. J.; J. Mater. Chem. 2001, 11, 2476.

10. Ruan, S.-K.; Zhou, J.-G.; Zhong, A.-M.; Duan, J-F.; Yang, X.-B.; Su, M.Z.; J. Alloys Compd. 1998, 271-273, 72.

11. Florian, P.; Gervais, M.; Douy, A.; Massiot, D.; Coutures, J.-P.; J. Phys. Chem. B 2001, 105, 379.

12. Lenus, A. J.; Rajan, K. G.; Yousuf, M.; Sornadurai, D.; Purniah, B.; Mat. Lett. 2002, 54, 70.

13. Amano, T.; Isobe, H.; Sakai, N.; Shishido, T.; J. Alloys Compd. 2002, 344, 394.

14. Hreniak, D.; Jasiorski, M.; Hreniak, A.; Dudzinski, W.; Maruszewski, K.; Strek, W,; J. Sol-Gel Sci. Technol. 2003, 26, 971.

15. Towata, A.; Hwang, H. J.; Yasuoka, M.; Sando, M.; K. Niihara, K.; Composites: Part A 2001, 32, 1127.

16. Nassar, E. J.; Avila, L. R.; Pereira, P. S. F.; de Lima, O. J.; Ciuffi, K. J.; Mello, C.; Carlos, L. D.; J. Lumin. 2005, 111, 159.

17. Airoldi, C.; de Farias, R. F.; Quim. Nova 2004, 27, 84.

18. Dhanaraj, J.; Jagannathan, R.; Kutty, T. R. N.; Lu, C.-H.; J. Phys. Chem. B 2001, 105, 11098.

19. Peacock, R. D.; Structure and Bonding 1975, 22.

20. Rice, D. K.; DeShazer, L. G.; J. Chem. Phys. 1970, 52, 172

21. Williams, D. K.; Yuan, H. B.; Tissue, B. M.; J. Lumin. 1999, 75, 83.

22. Buijs, M.; Vree, J. L.; Blasse, G.; Chem. Phys. Lett. 1987.

23. Brittain, H. G.; Perry, D. L.; J. Electrochem. Soc. 1969, 116, 474 